\title{
New Particle Formation and Growth from Dimethyl Sulfide Oxidation by Hydroxyl Radicals
}

Bernadette Rosati,* Sigurd Christiansen, Robin Wollesen de Jonge, Pontus Roldin, Mads Mørk Jensen, Kai Wang, Shamjad P. Moosakutty, Ditte Thomsen, Camilla Salomonsen, Noora Hyttinen, Jonas Elm, Anders Feilberg, Marianne Glasius, and Merete Bilde*

Cite This: ACS Earth Space Chem. 2021, 5, 801-811

Read Online

ACCESS | Lill Metrics \& More | 回 Article Recommendations ｜（s Supporting Information

ABSTRACT: Dimethyl sulfide (DMS) is produced by plankton in oceans and constitutes the largest natural emission of sulfur to the atmosphere. In this work, we examine new particle formation from the primary pathway of oxidation of gas-phase DMS by $\mathrm{OH}$ radicals. We particularly focus on particle growth and mass yield as studied experimentally under dry conditions using the atmospheric simulation chamber AURA. Experimentally, we show that aerosol mass yields from oxidation of 50-200 ppb of DMS are low (2$7 \%)$ and that particle growth rates $(8.2-24.4 \mathrm{~nm} / \mathrm{h})$ are comparable with ambient observations. An HR-ToF-AMS was

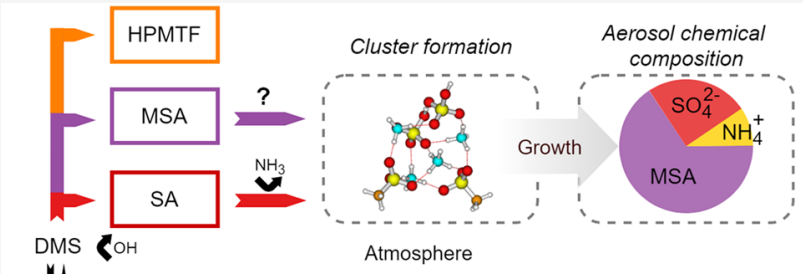
calibrated using methanesulfonic acid (MSA) to account for fragments distributed across both the organic and sulfate fragmentation table. AMS-derived chemical compositions revealed that MSA was always more dominant than sulfate in the secondary aerosols formed. Modeling using the Aerosol Dynamics, gas- and particle-phase chemistry kinetic multilayer model for laboratory CHAMber studies (ADCHAM) indicates that the Master Chemical Mechanism gas-phase chemistry alone underestimates experimentally observed particle formation and that DMS multiphase and autoxidation chemistry is needed to explain observations. Based on quantum chemical calculations, we conclude that particle formation from DMS oxidation in the ambient atmosphere will most likely be driven by mixed sulfuric acid/MSA clusters clustering with both amines and ammonia.

KEYWORDS: atmospheric simulation chamber, dimethyl sulfide, methanesulfonic acid, photo-oxidation, nucleation, growth rate

\section{INTRODUCTION}

Dimethyl sulfide (DMS) is omnipresent in surface seawater and the marine atmosphere. ${ }^{1-3}$ DMS is believed to be produced by phytoplankton from the decomposition of dimethyl sulfoniopropionate ${ }^{4}$ and constitutes the largest natural emission source of sulfur compounds into the ambient atmosphere. ${ }^{5}$ Once emitted into the atmosphere, DMS can react with atmospheric oxidants with the dominating oxidation process being reactions with the hydroxyl radical $(\mathrm{OH})$. The reaction of DMS with $\mathrm{OH}$ radicals can proceed via either an addition pathway or a hydrogen abstraction pathway ${ }^{6}$

$$
\begin{aligned}
& \mathrm{CH}_{3} \mathrm{SCH}_{3}+\dot{\mathrm{O} H} \rightarrow \mathrm{CH}_{3} \mathrm{SC}_{2}+\mathrm{H}_{2} \mathrm{O} \\
& \quad(\text { abstraction) } \\
& \mathrm{CH}_{3} \mathrm{SCH}_{3}+\dot{\mathrm{O} H} \stackrel{\mathrm{M}}{\rightleftharpoons} \mathrm{CH}_{3} \dot{\mathrm{S}}(\mathrm{OH}) \mathrm{CH}_{3} \quad \text { (addition) }
\end{aligned}
$$

The relative importance of the two pathways at atmospheric pressure depends on temperature. The final product distribution depends on the succeeding chemical reactions influenced by several factors such as temperature, pressure, and
$\mathrm{NO}_{x}$ level. ${ }^{6,7}$ Eventually, the oxidation process leads to the lowvolatility acids methanesulfonic acid $\left(\mathrm{CH}_{3} \mathrm{SO}_{3} \mathrm{H}, \mathrm{MSA}\right)$ and sulfuric acid $\left(\mathrm{H}_{2} \mathrm{SO}_{4}, \mathrm{SA}\right)^{6,7}$ as well as hydroperoxymethyl thioformate $\left(\mathrm{HOOCH}_{2} \mathrm{SCHO}, \mathrm{HPMTF}\right){ }^{8}$

DMS first gained notoriety for its role in the so-called CLAW hypothesis. ${ }^{9}$ This hypothesis presumes a feedback loop where warmer temperatures increase DMS concentrations, leading to more sulfate aerosols and hence more sulfatecontaining cloud condensation nuclei (CCN), which increase cloudiness and thereby lead to colder temperatures, potentially mitigating consequences of a warming climate. Although the CLAW concept has been questioned, ${ }^{10-12}$ it has triggered much research in the field; however, it has so far been difficult to prove or disprove the idea.

Received: December 8, 2020

Revised: $\quad$ March 8, 2021

Accepted: March 10, 2021

Published: March 25, 2021 
Table 1. Experimental Conditions ${ }^{a}$

\begin{tabular}{|c|c|c|c|c|c|c|c|c|}
\hline exp. & date & $\begin{array}{l}\text { DMS } \\
{[\mathrm{ppb}]}\end{array}$ & $\Upsilon$ & $\begin{array}{c}m_{\mathrm{a}} \\
{\left[\mu \mathrm{g} / \mathrm{m}^{3}\right]}\end{array}$ & $\begin{array}{c}N_{\text {tot }} \\
{\left[\# / \mathrm{cm}^{3}\right]}\end{array}$ & $\begin{array}{c}\rho \\
{\left[\mathrm{g} / \mathrm{cm}^{3}\right]}\end{array}$ & $\begin{array}{c}\text { GR } \\
{[\mathrm{nm} / \mathrm{h}]}\end{array}$ & $\mathrm{MSA} / \mathrm{SO}_{4}^{2-}$ \\
\hline 1 & 05.04 .2018 & 200 & & 28.4 & $2.2 \times 10^{7}$ & 1.54 & $11.7 \pm 0.1$ & 3.8 \\
\hline 2 & 19.05 .2018 & 200 & 0.079 & 31.8 & $1.5 \times 10^{7}$ & 1.56 & $24.4 \pm 2.5$ & 3.0 \\
\hline 3 & 21.05 .2018 & 100 & 0.044 & 8.8 & $1.5 \times 10^{7}$ & 1.51 & $10.1 \pm 1.2$ & 10.4 \\
\hline 4 & 23.05 .2018 & 50 & 0.039 & 4.4 & $0.5 \times 10^{7}$ & 1.52 & & 7.1 \\
\hline 5 & 26.05 .2018 & 100 & 0.051 & 11.5 & $0.9 \times 10^{7}$ & 1.54 & & 4.3 \\
\hline 6 & 27.09 .2018 & 50 & & 2.3 & $0.4 \times 10^{7}$ & 1.61 & $8.8 \pm 0.7$ & 1.4 \\
\hline 7 & 15.11 .2018 & 100 & & 5.6 & $0.9 \times 10^{7}$ & 1.56 & $15.1 \pm 0.8$ & 3.1 \\
\hline 8 & 19.11 .2018 & 50 & & 3.3 & $0.9 \times 10^{7}$ & 1.52 & $8.2 \pm 0.2$ & 6.2 \\
\hline 9 & 13.02.2019 & 200 & 0.023 & 6.5 & $0.6 \times 10^{7}$ & 1.55 & $13.1 \pm 0.6$ & 3.2 \\
\hline 10 & 04.03.2019 & 400 & & 11.3 & $0.6 \times 10^{7}$ & 1.62 & $15.9 \pm 1.1$ & 1.3 \\
\hline 11 & 07.03.2019 & 400 & & 11.2 & $0.8 \times 10^{7}$ & 1.51 & $15.5 \pm 1.8$ & 3.2 \\
\hline
\end{tabular}

${ }^{a} \mathrm{RH}$ and temperature in the chamber were $<15 \%$ and $293 \mathrm{~K}$ in all experiments, respectively. In total, $418 \mu \mathrm{L}$ of $\mathrm{H}_{2} \mathrm{O}_{2}$ were used in Exp. $1-9$ and $1500 \mu \mathrm{L}$ in Exp. 10 and 11. The aerosol mass yield $(\Upsilon)$, maximum aerosol mass $\left(m_{\mathrm{a}}\right)$, total number concentration $\left(N_{\text {tot }}\right)$, aerosol density $(\rho)$ as calculated from AMS data (see the text), growth rate (GR), and ratio of MSA to $\mathrm{SO}_{4}{ }^{2-}$ as obtained from AMS measurements.

It is well known that SA is a prime driver of atmospheric new particle formation, ${ }^{13}$ but little is known about the contribution from MSA to new particle formation. The atmospheric concentrations of MSA are usually on the order of $10^{5}-10^{7}$ molecules $\mathrm{cm}^{-3},{ }^{14-20}$ which are comparable to typical concentrations of $\mathrm{H}_{2} \mathrm{SO}_{4}{ }^{13}$ As anthropogenically emitted $\mathrm{SO}_{2}$ is expected to decline in the future, ${ }^{21-23}$ the contribution of MSA to new particle formation is expected to increase. ${ }^{23}$ It is crucial to obtain a better understanding of nucleation and the early growth processes of aerosol particles as these mechanisms govern the formation of cloud condensation nuclei (CCN), which constitute the largest uncertainty in global climate estimations. ${ }^{26}$ For instance, up to half of the formed number of CCN may originate from nucleation ${ }^{27}$ and even minor changes in the parameterization of the early growth of 1.7-3.0 nm particles can lead to a factor of 2 change in the modeled number of $\mathrm{CCN}^{28} \mathrm{New}$ particle formation occurs via the formation of stable clusters that subsequently grow to larger sizes. ${ }^{29}$ SA has been shown to cluster efficiently with atmospheric bases such as ammonia ${ }^{30}$ and amines. ${ }^{31-38}$ MSA nucleation has in the past few years been extensively studied using a flow reactor setup, with complementary quantum chemical calculations by the group of Finlayson-Pitts. These studies have shown that water, ammonia, and amines (methyl-, dimethyl-, and trimethylamine) significantly enhance MSA nucleation. ${ }^{39-45}$ The combined effect of MSA and SA on new particle formation has been studied using quantum chemical methods. Bork et al. ${ }^{46}$ showed that at MSA concentrations relevant to the marine environment, cluster formation between SA and dimethylamine could be enhanced from 15 to $300 \%$ at 298 and $258 \mathrm{~K}$, respectively, by the presence of MSA. Using a combination of flow tube experiments and quantum chemical calculations, Wen et al. ${ }^{47}$ recently showed that adding MSA to formed SA-water particles led to a bimodal particle distribution with an initial narrow peak that was attributed to MSA-water particles and a broad larger peak that was attributed to SA-water particles. Adding SA to formed MSAwater particles did not show this bimodal behavior.

In this work, we present state-of-the-art chamber experiments targeting the oxidation of DMS with $\mathrm{OH}$ radicals under dry, low- $\mathrm{NO}_{x}$ conditions. Using complementary quantum chemical calculations and the Aerosol Dynamics gas- and particle-phase chemistry model for laboratory CHAMber studies (ADCHAM) ${ }^{48,49}$ we seek to elucidate the mechanism for new particle formation from the oxidation of DMS and the role of MSA in particular. Since ammonia is omnipresent in the atmosphere and trace amounts of ammonia seem unavoidable in chamber studies, ${ }^{30}$ our modeling includes the effect of ammonia on new particle formation. A companion manuscript $^{50}$ provides further details on ADCHAM modeling.

\section{MATERIALS AND METHODS}

2.1. Chamber Experiments. All experiments were conducted at the AURA atmospheric simulation chamber, which is described in detail elsewhere. ${ }^{51}$ In short, the AURA chamber facility consists of a $5 \mathrm{~m}^{3}$ Teflon FEP bag situated inside a temperature-controlled room. Before each experiment, the chamber was filled with purified dry air (active carbon, HEPA filter, and zero-air generator (Aadco Model 737-14)) at atmospheric pressure and a temperature of $293 \mathrm{~K}$. Nitrogen oxide $\left(\mathrm{NO}_{x}\right)$ levels were continuously monitored with a chemiluminescent monitor (AC32M, Environnement S.A.; detection limit, $1 \mathrm{ppb})$. All experiments were performed at dry conditions $(\mathrm{RH}<15 \%)$. The chamber has $24 \mathrm{UV}$ lamps (wavelengths $300-400 \mathrm{~nm}$ ) mounted on the top and bottom of the Teflon bag, and $\mathrm{OH}$ radicals were produced by photolysis of $\mathrm{H}_{2} \mathrm{O}_{2}$. The $\mathrm{H}_{2} \mathrm{O}_{2}$ (30\% in $\mathrm{H}_{2} \mathrm{O}$, Merck, 1.07209.0250) was evaporated from a heated round-bottom flask $(403 \mathrm{~K})$ and flushed into the chamber using heated $\mathrm{N}_{2}$ $(333-343 \mathrm{~K}, 10 \mathrm{~L} / \mathrm{min})$. The $\mathrm{OH}$ radical concentrations were investigated in separate experiments using the decay of 1butanol, and results indicate that $\mathrm{OH}$ radical concentrations were in the range of typical tropospheric concentrations ${ }^{52}$ $\left(4.64-5.71 \times 10^{6}\right.$ molecules $\left./ \mathrm{cm}^{3}\right)$. More details on $\mathrm{OH}$ radical estimation can be found in the SI (Table S1, Fig. S1).

In this work, DMS (Sigma-Aldrich, anhydrous $\geq 99.0 \%$, 274 380) was added to the chamber in four different concentrations ranging from 50 to $400 \mathrm{ppb}$ by transferring a known amount of DMS to a $10 \mathrm{~mL}$ glass manifold. DMS was evaporated and flushed into the chamber by a heated $\mathrm{N}_{2}$ flow (333-343 K, $10 \mathrm{~L} / \mathrm{min}$ ) to hinder condensation in the tubing during the injection. Table 1 presents an overview of the experimental conditions. In the experiments, the UV lights were turned on first and then $\mathrm{H}_{2} \mathrm{O}_{2}$ was injected followed by DMS. The point in time when DMS was injected was marked time- 0 in the analysis. The total instrument sampling rates ranged between 4.2 and $6.9 \mathrm{~L} / \mathrm{min}$, resulting in an approximate 
chamber air residence time of between 12 and $20 \mathrm{~h}$ during the experiments.

2.2. Particle Size Distributions. Particle size distributions were measured using a TSI scanning mobility particle sizer (SMPS, model 3938). The SMPS system consisted of an electrostatic classifier (model 3082) equipped with either a long (model 3081) or nano (model 3085A) differential mobility analyzer (DMA), an aerosol neutralizer ( $\mathrm{Kr}-85$ source, model 3077A) connected to a nano water-based condensation particle counter (WCPC, model 3788). Aerosol instrument manager (AIM) version 10.2.0.11 was used to correct for diffusion losses and multiple charge correction. The combination of the two DMA columns enables measurements of particles in the range $2-422 \mathrm{~nm}$. The SMPS was always measuring with a sheath-to-aerosol flow ratio of 10:1. An impactor $(0.071 \mathrm{~cm})$ was installed in front of the DMA, giving a $D_{50}$ of $982 \mathrm{~nm}$ assuming a density of $1 \mathrm{~g} / \mathrm{cm}^{3}$.

During the initial nucleation and growth period, only the WCPC was measuring to capture the increase in particle concentration at $1 \mathrm{~Hz}$ frequency. After the particle number concentration peaked, the WCPC was connected to the classifier with the nano-DMA column attached (aerosol-tosheath flow rate of $1.5: 15 \mathrm{~L} / \mathrm{min}$, size range $2-65 \mathrm{~nm}$ ). Before the particle size distribution grew out of the size range, the nano-DMA was replaced by the long-DMA column for the remainder of the experiment (aerosol-to-sheath flow rate of 0.6:6 L/min, size range $10-422 \mathrm{~nm}$ ). The total particle mass was obtained from the SMPS measurement assuming spherical particles, and the density was as retrieved from the HR-ToFAMS data (see Table 1). The SMPS mass concentration of the polydisperse aerosol particles was wall-loss-corrected following Crump et al. ${ }^{53}$ and Leskinen et al. ${ }^{54}$

2.3. DMS Measurements. In five experiments, the concentration of gas-phase DMS in the AURA chamber was monitored by a proton transfer reaction mass spectrometer (PTR-MS, Ionicon Analytik, Innsbruck, Austria ${ }^{55-57}$ ). PTRMS is based on chemical ionization of compounds by proton transfer from hydronium $\left(\mathrm{H}_{3} \mathrm{O}^{+}\right)$in a drift tube and subsequent detection of ionized compounds using either a high-sensitivity quadrupole (PTR-QMS; Exp. 2-5) or time-offlight (PTR-ToF 4000; Exp. 9) mass spectrometer. The PTRQMS was operated under standard conditions with a drift tube voltage of $600 \mathrm{~V}$, a drift tube temperature of $75^{\circ} \mathrm{C}$, and a drift tube pressure of 2.2 mbar with an $\mathrm{E} / \mathrm{N}$ number of $135 \mathrm{Td}$. PTR-ToF was run with drift tube conditions of $650 \mathrm{~V}, 80^{\circ} \mathrm{C}$, and $2.4 \mathrm{mbar}$ and thus an $\mathrm{E} / \mathrm{N}$ number of $143 \mathrm{Td}$. DMS $\left(\mathrm{CH}_{3} \mathrm{SCH}_{3}\right)$ was detected as the protonated molecular ion on a mass-to-charge ratio $(\mathrm{m} / \mathrm{z})$ of 63 . The data was analyzed using PTR-MS Viewer 3 (Ionicon), and a transmission calibration was performed based on specific reaction rate constants and mass discrimination factors prior to the experiments as previously described elsewhere. ${ }^{58,59}$ To minimize sampling losses, the heated inlet was kept at $80{ }^{\circ} \mathrm{C}$ and prolonged with a $2 \mathrm{~m}$ long Teflon tube, wrapped in heating tape set to $60^{\circ} \mathrm{C}$, and an additional sheath flow of 200 $\mathrm{mL} / \mathrm{min}$ was chosen. No wall loss corrections were applied to gas-phase data.

2.4. Particulate Chemical Composition. A highresolution time-of-flight aerosol mass spectrometer (HRToF-AMS, Aerodyne Research Inc.) was used for real-time analysis of the chemical composition of the total nonrefractory particulate matter. The working principle of the HR-ToF-AMS has been reported in detail elsewhere. ${ }^{60}$ The AMS was connected to the AURA smog chamber by $4 \mathrm{~mm}$ ID stainless steel and copper tubing of $1.7 \mathrm{~m}$ length (flow rate $0.08 \mathrm{~L} / \mathrm{min}$, residence time $15 \mathrm{~s}$ ) and operated in V-mode in the mass range $m / z$ of $8-407$ with an acquisition cycle of $10 \mathrm{~s}$ MS (5 s open, 5 $\mathrm{s}$ closed) and $10 \mathrm{~s}$ ePToF saved in $1 \mathrm{~min}$ averages. AMS data were processed by data analysis software packages SQUIRREL (version 1.61) and PIKA (version 1.21) in Igor Pro. The PIKA default AMS collection efficiency (CE) of 1 was used.

The AMS was calibrated for MSA to achieve accurate quantification and account for its fragments being distributed across both the organic and sulfate species in the default AMS fragmentation table. The calibration was based on the method validated by Hodshire et al., ${ }^{61}$ i.e., $\mathrm{CE}=1$, and AMS response to MSA independent of aerosol acidity. The MSA quantification used the specific marker ion $\mathrm{CH}_{3} \mathrm{SO}_{2}^{+}$. ${ }^{62,63}$ The calibration setup consisted of an aqueous solution of $4 \mathrm{mM}$ MSA (>99\%, Sigma-Aldrich, 471356), an atomizer (TSI 3076), a silica dryer, the above-mentioned SMPS system where the DMA selected dry monodisperse $300 \mathrm{~nm}$ particles ( $\mathrm{RH}<40 \%)$, and dilution using particle-free air. The calibration resulted in the ratio of the marker ion to the total MSA signal, $f\left(\mathrm{CH}_{3} \mathrm{SO}_{2}^{+}\right)$, equal to $7.35 \%$, and the relative ionization efficiency of MSA, $\mathrm{RIE}_{\mathrm{MSA}}$ equal to 1.06. The measured mass spectrum of MSA was applied to the HR fragmentation table, as shown in the Supporting Information (Table S2). The AMS data displayed are not corrected for wall losses.

2.5. ADCHAM Model Setup. Details on the ADCHAM model setup and DMS chemistry are provided in Wollesen de Jonge et al. ${ }^{50}$ Model parameters specific to the current work, which represent dry conditions only, are given in the SI. In brief, the ADCHAM model ${ }^{48,49}$ was used to simulate the DMS experiments in the AURA chamber using the observed $\mathrm{RH}$ and temperature as input to the model. For this purpose, the model data was compared to results from HR-ToF-AMS to analyze the mass of the single components present in the aerosol particle mass. New particle formation was modeled using the atmospheric cluster dynamics code $\mathrm{ACDC},{ }^{64}$ considering neutral and ion-induced clustering of $\mathrm{SA}$ and $\mathrm{NH}_{3}$ molecules. ${ }^{34}$ ACDC was dynamically coupled to the aerosol dynamics module in ADCHAM using the methodology described in Roldin et al. ${ }^{49}$ The DMS gas-phase chemistry was primarily based on MCMv3.3.1. ${ }^{65-67}$

2.6. Quantum Chemical Calculations. Quantum chemical calculations were performed to obtain the molecular structures and thermochemistry of clusters consisting of SA, MSA, and ammonia (A). The Gaussian16 program ${ }^{68}$ (using G09 defaults) was employed to obtain the molecular cluster structures and calculate the harmonic vibrational frequencies. We used the $\omega$ B97X-D ${ }^{69}$ density functional as it has been shown to yield the lowest errors in the binding energies of atmospheric molecular clusters compared to higher-level $\operatorname{CCSD}(\mathrm{T})$ complete basis set estimates. ${ }^{70-73}$ The density functional theory calculations were performed using the 6-31+ $+\mathrm{G}(\mathrm{d}, \mathrm{p})$ basis set, which has shown good agreement with basis sets of significantly larger sizes. ${ }^{74,75}$

Thermochemistry of the $(\mathrm{SA})_{1-4}(\mathrm{~A})_{1-4}$ clusters was taken from the Atmospheric Cluster Database (ACDB). ${ }^{76}$ The cluster structures of the $(\mathrm{MSA})_{1-4}(\mathrm{~A})_{1-4}$ clusters were taken from ref 77 and recalculated at the DLPNO-CCSD $\left(\mathrm{T}_{0}\right) /$ augcc-pVTZ// $\omega$ B97X-D/6-31++G(d,p) level of theory. The $(\mathrm{SA})_{1-3}(\mathrm{MSA})_{1-3}$ and $(\mathrm{SA})_{x}(\mathrm{MSA})_{y}(\mathrm{~A})_{1-4}$, with $x+y \leq 4$, were fully obtained in this work. The cluster structures were 
initially sampled using a CHARMM force field with the artificial bee colony $(A B C)$ algorithm as implemented in the ABCluster program. ${ }^{78,79}$ The clusters were sampled using similar settings to those presented by Kubečka et al. ${ }^{80}$ We used the semiempirical PM7 method to reduce the number of relevant conformers based on the $\mathrm{RMSD}^{81,82}$ of the clusters using the ArbAlign program. ${ }^{83}$ Subsequently, the cluster structures and vibrational frequencies were calculated at the $\omega \mathrm{B} 97 \mathrm{X}-\mathrm{D} / 6-31++\mathrm{G}(\mathrm{d}, \mathrm{p})$ level of theory.

For all of the cluster structures, the binding energies were calculated using a high-level DLPNO-CCSD $\left(\mathrm{T}_{0}\right)^{84,85}$ calculation with an aug-cc-pVTZ basis set using the ORCA program version 4.2.1. ${ }^{86}$ The auxiliary aug-cc-pVTZ/C and aug-cc$\mathrm{pVTZ} / \mathrm{JK}$ basis sets were used for density fitting and Coulomb/exchange fitting, respectively. We have previously demonstrated that this level of theory yields binding energy results in good agreement with higher-level coupled-cluster complete basis set estimates. ${ }^{72,73}$ All of the thermochemical parameters have been calculated at $298.15 \mathrm{~K}$ and $1 \mathrm{~atm}$. All of the cluster structures and the associated thermochemical data are deposited in the Atmospheric Cluster Database (ACDB). ${ }^{76}$

\section{RESULTS AND DISCUSSION}

A series of 11 experiments were conducted in the AURA chamber. Table 1 provides an overview of the experimental conditions as well as the aerosol mass yield, maximum aerosol mass, total particle number concentration, particle density, initial particle growth rate, and MSA to $\mathrm{SO}_{4}^{2-}$ ratio.

3.1. Physical Properties. Figure 1 presents an example of the decrease in DMS concentration and the associated increase

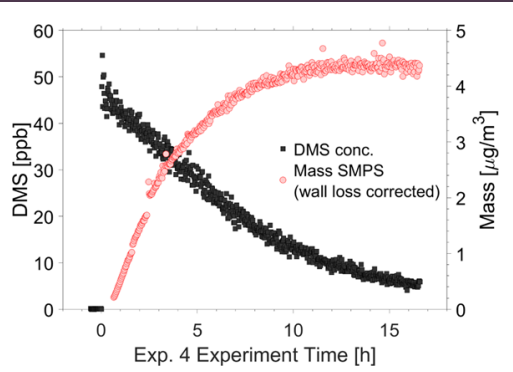

Figure 1. DMS concentration and wall-loss-corrected aerosol mass during Exp. 4, as measured from the combination of nano- and longSMPS (using the density as retrieved from HR-ToF-AMS data). The time of DMS injection is $t=0$.

in aerosol mass (based on SMPS data using the density as calculated from HR-ToF-AMS; see more information on this calculation below) during a typical experiment. The maximum particle mass in this example is approximately reached after 10 h. Corresponding results for the other experiments along with information about initial particle number concentration, $\mathrm{T}$, $\mathrm{RH}$, and ozone concentrations in the chamber are provided in Figures S2-S12 in the SI.

The aerosol mass yield $(\Upsilon)$ is defined as the mass of formed aerosol particles $\left(m_{\mathrm{a}}\right)$ divided by the mass of reacted DMS $(\triangle \mathrm{DMS})$ and was calculated for the point in time where the maximum mass of aerosol particles (after wall loss correction) was reached ${ }^{87}$

$$
\Upsilon=\frac{m_{\mathrm{a}}}{\Delta \mathrm{DMS}}
$$

Figure $2 \mathrm{~A}$ and Table 1 present the calculated aerosol mass yields for the different initial DMS concentrations in the AURA chamber. Particle mass concentrations are derived from SMPS measurements assuming spherical particles. The density of the particles was calculated based on the MSA and $\mathrm{SO}_{4}{ }^{2-}$ concentrations, as measured by the HR-ToF-AMS, considering that MSA has a density of $1.48 \mathrm{~g} / \mathrm{cm}^{388}$ and SA, measured as $\mathrm{SO}_{4}{ }^{2-}$ in the AMS, has a density of $1.84 \mathrm{~g} / \mathrm{cm}^{3}{ }^{88} m_{\mathrm{a}}$ was calculated using the densities listed in Table 1. During this study, DMS was not completely consumed when the maximum particle mass was reached, as can for example be seen in Figure 1 , which is most probably related to insufficient levels of the oxidant. Thus, yield data can only be retrieved from experiments where the PTR-MS instrument was used to measure DMS concentrations. Figure 2 shows aerosol mass yields ranging from 0.02 to 0.08 , with a slight trend toward increasing aerosol yield with increasing DMS consumption. The mass concentrations varied from 2.3 to $31.8 \mu \mathrm{g} / \mathrm{m}^{3}$, while the total number concentration of particles produced was relatively similar throughout all experiments ranging from 0.4 to $2.2 \times 10^{7} \# / \mathrm{cm}^{3}$ (see Table 1 ).

A previous study by Chen and Jang ${ }^{89}$ investigated the aerosol mass yield from photo-oxidation experiments of DMS in the presence of $40-300 \mathrm{ppb}$ of $\mathrm{NO}_{x}$. Although the DMS concentrations of Chen and Jang (116-170 ppb) are comparable to those in our study, their mass concentrations and mass yields strongly exceed our findings, reaching mass concentrations of $65.1-192 \mu \mathrm{g} / \mathrm{m}^{3}$ and yields of $0.536-0.753$. Although Chen and Jang used a different method for estimating organic aerosol mass and an assumed aerosol particle density of 1.2 , thus similar to that of DMS, the differences in mass yields are large. During the experiments in the current study, the $\mathrm{NO}_{x}$ values were always below 5 ppb; thus, it seems reasonable to conclude that $\mathrm{NO}_{x}$ has a large influence on the aerosol mass concentrations and mass yields. ADCHAM supports this conclusion as $\mathrm{NO}_{x}$ promotes the aerosol mass yield in the model by favoring $\mathrm{CH}_{3} \mathrm{SO}_{3}$ and ultimately $\mathrm{SA}$ and MSA production rather than $\mathrm{SO}_{2}$ formation. Besides, ADCHAM runs also showed that aerosol mass yields are sensitive to vapor wall loss rates and particularly dilution in the chamber (more details are presented in Section 3.2).

The temporal evolution of the two example particle size distributions (Exp. 2, 200 ppb DMS and Exp. 4, 50 ppb DMS), shown in Figure 2C,D, displays new particle formation with subsequent growth of the aerosol particles formed in the DMS photo-oxidation. After $10 \mathrm{~h}$, particles in Exp. 2 grew to approximately $140 \mathrm{~nm}$ of particle mode diameter, while a smaller aerosol particle mode diameter of approximately 100 nm was measured in Exp. 4. Our results show a second growth mode below the main nucleation mode. This is evident for all DMS concentrations used in our experiments, thus for all experiments listed in Table 1. Growth rates (GRs) of fine aerosol particles with diameters between 10 and $20 \mathrm{~nm}$ were calculated from the aerosol size distributions using the maximum-concentration method $\mathrm{d}^{90,91}$ and are displayed in Figure $2 \mathrm{~B}$ and Table 1. Due to the experimental procedure, i.e., the subsequent measurements with first CPC, then nanoSMPS, and then long-SMPS, it was not possible to follow the growth of particle sizes below $10 \mathrm{~nm}$. In Exp. 4 and 5, the size distribution measurement started later in time and hence the GR for this size range could not be determined. The measured GRs in our study ranged from 8 to $25 \mathrm{~nm} / \mathrm{h}$ for DMS concentrations between 50 and $400 \mathrm{ppb}$. The results pointed 
A

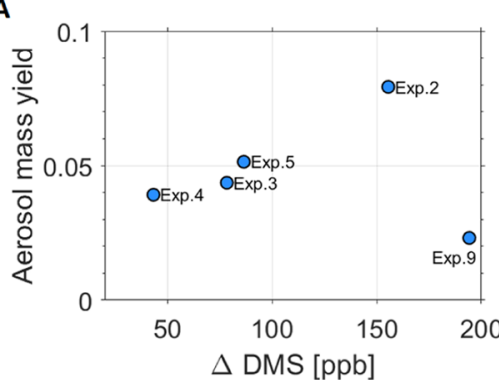

C

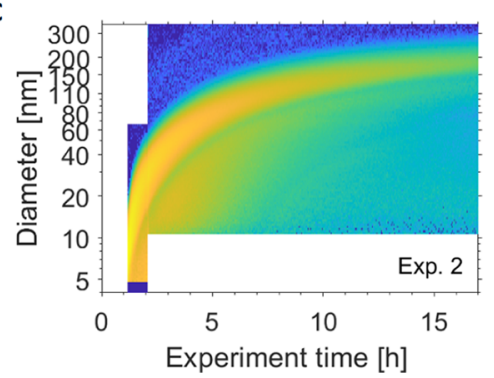

B

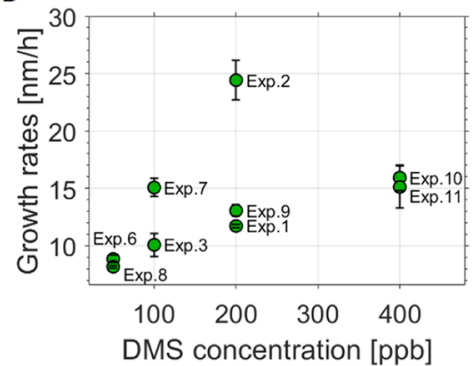

D

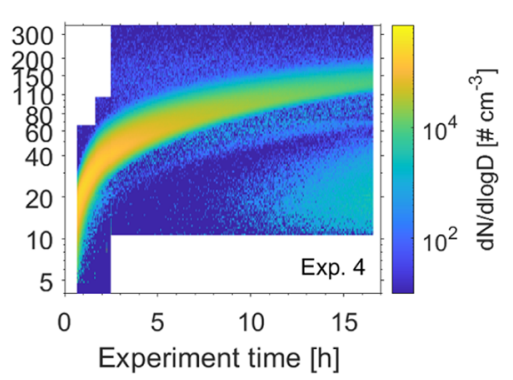

Figure 2. (A) Aerosol mass yields vs $\triangle \mathrm{DMS}$ (see also Table 1). As the DMS concentration was not completely consumed when the maximum mass was reached, only data from experiments where the PTR was employed are shown. (B) Calculated growth rates (GR) using the maximumconcentration method $^{90,91}$ for the size range from 10 to $20 \mathrm{~nm}$. The error bars denote the uncertainty from the GR fit. The $x$-axis denotes the theoretical DMS concentrations injected into the chamber. (C and D) Size distribution plots recorded with nano- and long-SMPS systems for Exp. 2 (200 ppb DMS) and Exp. 4 (50 ppb DMS).

toward slightly higher GRs with increasing DMS concentrations. Ambient measurements in marine, coastal areas found GRs between 1.8 and $20 \mathrm{~nm} / \mathrm{h}$ for particles with diameters from 7 to $20 \mathrm{~nm} .^{92,93}$ Hence, the GRs observed from DMS oxidation here are in good agreement with findings in ambient air.

3.2. Chemical Composition and Model Simulations. The particle chemical composition for all experiments derived from AMS measurements is illustrated in Figure 3 as relative

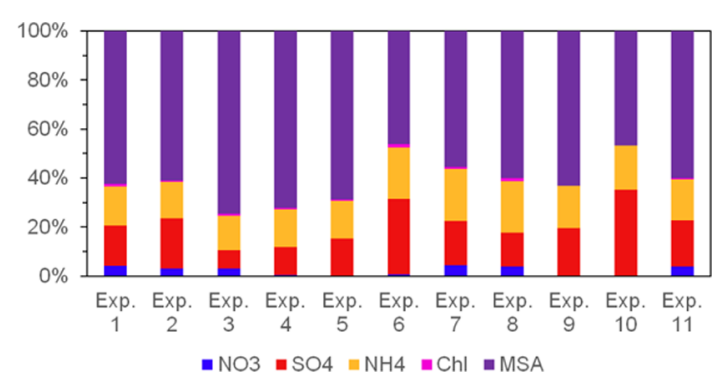

Figure 3. HR-ToF-AMS-measured particle composition shown as relative mass concentrationsof $\mathrm{NO}_{3}{ }^{-}, \mathrm{SO}_{4}{ }^{2-}, \mathrm{NH}_{4}^{+}$, chloride, and MSA. Data are $10 \mathrm{~min}$ averages at the time of maximum aerosol mass.

compositions of $\mathrm{NH}_{4}^{+}, \mathrm{NO}_{3}{ }^{-}$, chloride, and the DMS oxidation products MSA and SA (measured as $\mathrm{SO}_{4}{ }^{2-}$ ) at the time of maximum aerosol mass in each experiment. Overall, the results show that $\mathrm{OH}$ oxidation of DMS resulted in a dominant contribution from MSA to particle mass compared to $\mathrm{SO}_{4}{ }^{2-}$ in all cases. Figure $4 \mathrm{~B}$ shows an example of the temporal evolution of the chemical composition (from Exp. 2). Minor and variable contamination from $\mathrm{NO}_{3}{ }^{-}$was observed, and low levels of chloride were found above the literature detection limit ${ }^{60}$ in Exp. 1-3, 7, and 11. In addition, low concentrations of constituents categorized as organic aerosol (OA) were observed (full results are shown in Figures S13 and
$\mathrm{S} 14$ in the SI). The mass spectra of the measured OA include the ions $\mathrm{CO}^{+}, \mathrm{CO}_{2}^{+}$, and $\mathrm{CHO}^{+}$and a large number of minor contributions from fragments that could be unknown OA, which could include organic oxidation products from DMS other than MSA. $\mathrm{CO}_{2}{ }^{+}$from oxidation of carbon residues on the AMS vaporizer ${ }^{24}$ was found to be negligible during calibrations. Part of the OA could be measurement artifacts, including MSA calibration uncertainty and indications of memory effects ${ }^{95,96}$ from high OA experiments few days prior to the experiments of this study. Comparing the absolute mass of OA across the experiments suggests that fairly constant contamination in the AMS data cannot be ruled out. It could not be determined whether the source of the contamination was the simulation chamber or deposits within the instrument. Assuming the measured OA to be an artifact or contamination implies that $\mathrm{SO}_{4}{ }^{2-}$ and MSA were the only measured particlephase products at the time of maximum aerosol mass. The concentrations of OA have been omitted in Figure 3 not to obscure the comparison of relative compositions of low- and high-mass experiments. Table 1 presents measured MSA to $\mathrm{SO}_{4}{ }^{2-}$ ratios for all experiments, ranging from 1.3 to 10.4 . There is a slight tendency toward higher MSA to $\mathrm{SO}_{4}{ }^{2-}$ ratios for smaller initial DMS concentrations. These are however also associated with a larger influence of potential organic contamination or memory effects in the AMS instrument as discussed above.

The Master Chemical Mechanism version 3.3.1 (MCMv3.3.1) gas-phase chemistry alone was not sufficient to describe the aerosol mass measured using the HR-ToFAMS. At $293 \mathrm{~K}$, the use of MCMv3.3.1 reactions underestimated the rate of SA and MSA production and hence the particle number ( $\mathrm{PN}$ ) and mass formation onset. By implementing the oxidation of MSIA to $\mathrm{CH}_{3} \mathrm{SO}_{2}{ }^{97}$ and isomerization of $\mathrm{CH}_{3} \mathrm{SOO}$ to $\mathrm{CH}_{3} \mathrm{SO}_{2},{ }^{98}$ the overall rate of oxidation was increased. This ensured a decent representation of the initial rate of particle formation (Figure 4A,D) but 

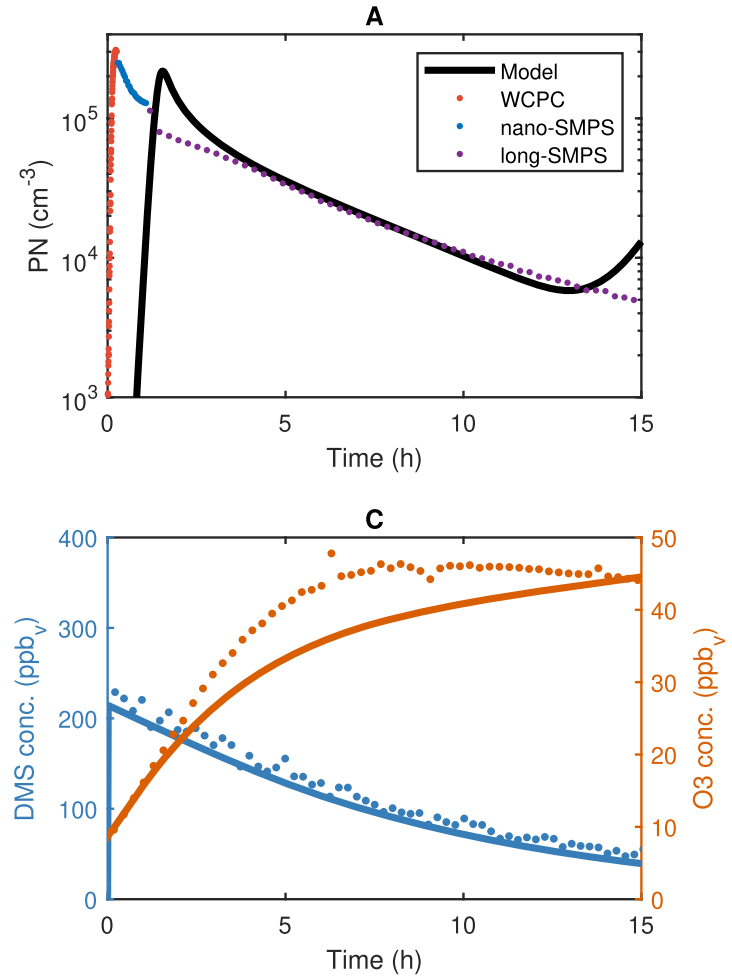
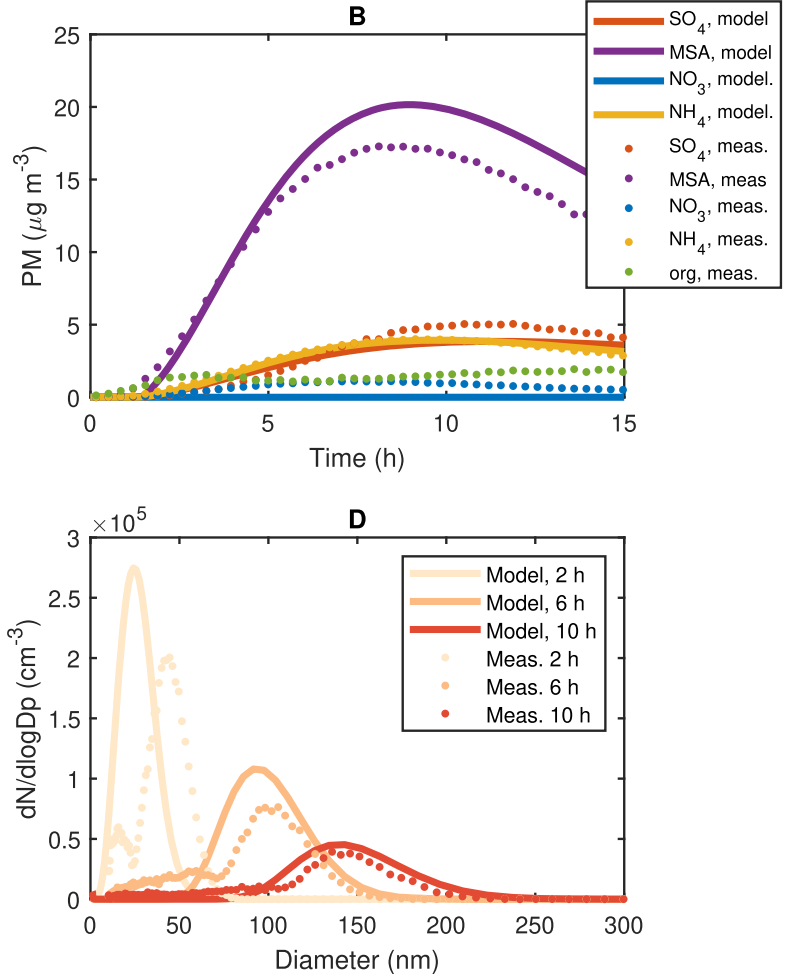

Figure 4. Measured and modeled results from Exp. 2. (A) Particle number concentration, (B) HR-ToF-AMS particle mass composition, (C) $\mathrm{O}_{3}$ (red) and DMS (blue) concentrations, and (D) SMPS particle size distribution.

overestimated the overall particle mass measured by the HRToF-AMS. To solve this, hydroperoxymethyl thioformate (HPMTF) formed through the newly discovered autoxidation pathway of DMS was implemented in the model. ${ }^{8}$ See Wollesen de Jonge et al. ${ }^{50}$ for details and the schematic of the major routes of formation of MSA and SA included in the model. Model results suggest that HPMTF remained in the gas phase, acting as a sulfur reservoir. Consequently, a large fraction of DMS did not form MSA and SA, which lowered the overall secondary aerosol mass yield obtained in the model to the concentration observed in the experiments (Figure 4B). MSA dominates the chemical composition in the secondary aerosol mass measured by the HR-ToF-AMS. The model indicates that a high $\mathrm{HO}_{2}$ gas-phase concentration (from the reaction of $\mathrm{OH}$ radicals and $\mathrm{O}_{3}$ ) favored the $\mathrm{CH}_{3} \mathrm{SO}_{3}+\mathrm{HO}_{2}$ reaction and hence MSA production.

ADCHAM was able to reproduce the DMS decay by $\mathrm{OH}$ radical-initiated oxidation (Figure $4 \mathrm{C}$ ) and thus the $\mathrm{OH}$ radical concentration in the AURA chamber. The model reported an average $\mathrm{OH}$ concentration of $2.3 \times 10^{6} \mathrm{~cm}^{-3}$ in accordance with measurement observations (SI). Model results for Exp. 3 and 4 are presented in the SI (Figures S15 and S16). The second particle mode observed in Figure 2C,D is not clearly reproduced by the ADCHAM model. The reason for the experimentally observed second mode should be further investigated in future studies. As indicated by the observations (Figure 2A), the modeled aerosol mass yields increase with increasing DMS concentrations (SI; Fig. S17). This can be explained by the generally increasing aerosol particle condensation sink with increasing DMS loading, which results in decreasing influence from the SA and MSA wall losses. When taking into account the wall losses of particles and vapors and the chamber dilution, the modeled aerosol mass yields fall close to the same value of 0.3 after $13 \mathrm{~h}$, irrespective of the initial DMS loading (SI, Figure S17). It can be noted that all DMS oxidation pathways likely lead to the formation of SA and MSA, which without any losses would result in aerosol mass yields of 1.5. However, especially the $\mathrm{OH}$ oxidation pathways going via $\mathrm{HPMTF}$ and $\mathrm{SO}_{2}$ as intermediate products are too slow to contribute to any substantial aerosol particle mass formation in the AURA experiments.

Unexpected species measured by the HR-ToF-AMS included $\mathrm{NH}_{4}^{+}, \mathrm{NO}_{3}{ }^{-}$, and various organic compounds. Aerosol $\mathrm{NH}_{4}{ }^{+}$concentrations were captured well by the model, by incorporating an initial amount of ammonium on the Teflon walls, causing a gradual diffusion of $\mathrm{NH}_{3}$ into the chamber. $\mathrm{NO}_{x}$ contamination was also included in the model but did not explain the concentration of $\mathrm{NO}_{3}{ }^{-}$measured by AMS. Regarding organics, it should be noted that they only contributed significantly to particle composition when the overall aerosol mass concentration was low (Figure S14). In fact, the mass concentrations in, for example, Exp. 6 are so low that they are close to the detection limit and thus the uncertainty in these measurements is high. The detection limit for organic mass measured with the AMS increases with an increased number of fragment ions fitted in the mass spectrum. ${ }^{95}$ With near 300 fitted organic fragment ions in these experiments, the detection limit for the organic fraction is estimated to be in the range of $0.25-0.5 \mu \mathrm{g} \mathrm{m}^{-3}$ as based on Drewnick et al. ${ }^{95}$ Another factor that might contribute to the high appearance of organic mass in low-mass laboratory experiments is the memory effect in the AMS instrument, as described by Pieber et al. ${ }^{94}$

3.3. Cluster Formation Mechanism. Using the ACDC code and the newly calculated quantum chemical data, we can gain explicit insight into the particle formation mechanism from $\mathrm{OH}$ oxidation of DMS. As the exact concentrations of the precursors are unknown, we assume that we form roughly 


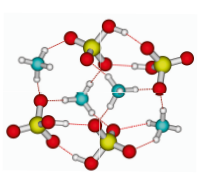

$(\mathrm{SA})_{4}(\mathrm{MSA})_{0}(\mathrm{~A})_{4}$

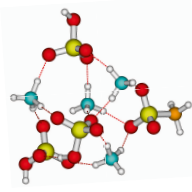

$(\mathrm{SA})_{3}(\mathrm{MSA})_{1}(\mathrm{~A})_{4}$

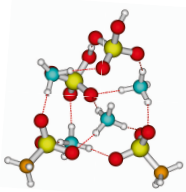

$(\mathrm{SA})_{2}(\mathrm{MSA})_{2}(\mathrm{~A})_{4}$

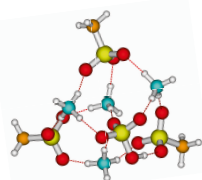

$(\mathrm{SA})_{1}(\mathrm{MSA})_{3}(\mathrm{~A})_{4}$

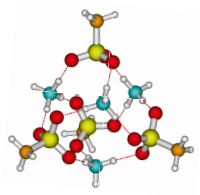

$(\mathrm{SA})_{0}(\mathrm{MSA})_{4}(\mathrm{~A})_{4}$

\begin{tabular}{lrrrrr}
\hline SA $=$ MSA & $8 \%$ & $58 \%$ & $31 \%$ & $<3 \%$ & $0 \%$ \\
High MSA & $0 \%$ & $11 \%$ & $56 \%$ & $31 \%$ & $0 \%$ \\
High SA & $56 \%$ & $40 \%$ & $<2 \%$ & $<2 \%$ & $0 \%$
\end{tabular}

Figure 5. Molecular structures of the largest clusters considered, calculated at the DLPNO-CCSD $\left(\mathrm{T}_{0}\right) /$ aug-cc-pVTZ// $\omega \mathrm{B} 97 \mathrm{X}-\mathrm{D} / 6-31++\mathrm{G}(\mathrm{d}, \mathrm{p})$ level of theory. The contribution (in \%) of each of the clusters to the new particle formation rate at three different conditions (high SA, high MSA, and $\mathrm{SA}=\mathrm{MSA}$ ) at $1 \mathrm{ppb}$ mixing ratio of ammonia is presented.

$10^{8}-10^{9}$ molecules $\mathrm{cm}^{-3}$ of SA and MSA from oxidation of DMS by $\mathrm{OH}$ radicals. These concentrations are a few orders of magnitude larger than expected in the ambient atmosphere but realistic considering the experimental conditions (50-200 ppb of DMS) and the modeling results. Ammonia (A) has been shown always to be present in simulation chambers, ${ }^{30}$ so we assume that we have approximately $1 \mathrm{ppb}$ (range from 0.1 to $10 \mathrm{ppb}$ ) of ammonia in the chamber. Estimates of ammonia concentrations are based on data from Tange $\left(56.352222^{\circ} \mathrm{N}\right.$, $9.5875^{\circ} \mathrm{W} ; \sim 50 \mathrm{~km}$ from Aarhus; http://ebas.nilu.no/) and knowledge that measurements in a nearby analytical laboratory routinely show typical concentrations of ammonia in the range of 1-10 ppb. To fully explore the mechanism, we allow all different types of cluster compositions, i.e., $(\mathrm{SA})_{4}(\mathrm{~A})_{4}$, $(\mathrm{MSA})_{4}(\mathrm{~A})_{4}$ and $(\mathrm{SA})_{x}(\mathrm{MSA})_{y}(\mathrm{~A})_{4}$, with $x+y \leq 4$ clusters to grow outside the ACDC simulation box and to contribute to the new particle formation (NPF) rate. The absolute values of the ACDC simulation are shown in the SI at various concentration ratios of SA and MSA at 298.15 K.

For all of the studied SA to MSA ratios, the simulated NPF rates are very dependent on the mixing ratio of ammonia. At $0.1 \mathrm{ppb}$ or below of ammonia, no particles are formed. Increasing the ammonia mixing ratio by a factor of 10 yields four orders of magnitude higher NPF rates, over the considered ammonia concentrations $(0.1-10 \mathrm{ppb})$. These results are in good agreement with the modeling results (see Section 3.2), which also identified that the particle formation rate and secondary aerosol mass are much dependent on the ammonia concentration. In all cases, we see that the particle formation rate is low, which is consistent with the experimental observation that the secondary aerosol formation and growth from DMS oxidation by $\mathrm{OH}$ radicals is slow and many hours are required for the secondary aerosol mass to peak.

The formation mechanism of SA and MSA from the oxidation of DMS is inherently complex, and it remains unknown what the exact branching ratio is during the experiments. By simulating different ratios between SA and MSA, we can obtain insight into how this distribution affects the particle formation rate and mechanism. In the following, we will ignore cluster fluxes that contribute less than $5 \%$ to the particle formation rate. Figure 5 presents the molecular structures of the largest clusters studied and their individual contribution to the new particle formation rate under three different conditions: (1) high SA (10:1 SA/MSA ratio), (2) high MSA (1:10 SA/MSA ratio), and (3) SA = MSA (1:1 SA/
MSA ratio). Here, $1=1 \times 10^{8}$ molecules $\mathrm{cm}^{-3}$. In all cases, the ammonia concentration was fixed at $1 \mathrm{ppb}$.

With a 1:1 ratio of SA to MSA $\left(1 \times 10^{8}\right.$ molecules $\left.\mathrm{cm}^{-3}\right)$ and $0.1 \mathrm{ppb}$ of ammonia, $42 \%$ of the particles are formed from collisions with $(\mathrm{SA})_{3}(\mathrm{MSA})_{1}(\mathrm{~A})_{4}$ clusters, $29 \%$ of the particles are formed from collisions with $(\mathrm{SA})_{2}(\mathrm{MSA})_{2}(\mathrm{~A})_{4}$ clusters, $17 \%$ from $(\mathrm{SA})_{4}(\mathrm{~A})_{4}$ clusters, and $6 \%$ from $(\mathrm{SA})_{1}(\mathrm{MSA})_{3}(\mathrm{~A})_{4}$ clusters. With increasing ammonia concentration, this distribution is perturbed, leading to a higher contribution from the $(\mathrm{SA})_{3}(\mathrm{MSA})_{1}(\mathrm{~A})_{4}$ cluster with 58 and $65 \%$ for 1.0 and 10 $\mathrm{ppb}$ of ammonia, respectively. This clearly indicates that newly formed particles from DMS oxidation will consist of different mixtures of both SA and MSA molecules when SA and MSA are present in equal concentrations.

Having a 10 times higher concentration of MSA compared to that of SA, the mechanism changes such that $63 \%$ of the particles are formed from collisions with $(\mathrm{SA})_{1}(\mathrm{MSA})_{3}(\mathrm{~A})_{4}$ clusters, with $31 \%$ contribution from $(\mathrm{SA})_{2}(\mathrm{MSA})_{2}(\mathrm{~A})_{4}$ clusters, at $0.1 \mathrm{ppb}$ of ammonia. With increasing ammonia concentration, this mechanism is shifted toward 56 and $61 \%$ contributions from $(\mathrm{SA})_{2}(\mathrm{MSA})_{2}(\mathrm{~A})_{4}$ clusters at 1.0 and 10 $\mathrm{ppb}$ of ammonia, respectively.

With a 10 times higher concentration of SA compared to that of MSA, the particle formation mechanism is dominated by collisions with $(\mathrm{SA})_{4}(\mathrm{~A})_{4}$ clusters (77\%), with $16 \%$ contribution from $(\mathrm{SA})_{3}(\mathrm{MSA})_{1}(\mathrm{~A})_{4}$ clusters. This distribution is very similar for $1.0 \mathrm{ppb}(56 / 40 \%)$ and $10 \mathrm{ppb}(62 /$ $35 \%)$ of ammonia. In no cases do we see the formation of $(\mathrm{MSA})_{4}(\mathrm{~A})_{4}$ clusters. Even by lowering SA to $1 \times 10^{6}$ molecules $\mathrm{cm}^{-3}$ and increasing MSA to $1 \times 10^{10}$ molecules $\mathrm{cm}^{-3}$ (yielding a 1:10 000 ratio), the growing clusters still have one sulfuric acid molecule present. These findings clearly show that the formed particles will consist of potentially different mixtures of SA and MSA molecules depending on the concentration ratio of the precursors. Most importantly, as these different particles consist of different acids, they might have very different growth properties and potentially also hygroscopicities. Thus, this distribution might explain the experimentally observed broad distribution of small (nucleation mode) particles as these could originate from the different particle compositions, which will have different growth rates. As the cluster formation rates are in all cases quite low, the particle formation mechanism in the ambient atmosphere involving DMS oxidation by $\mathrm{OH}$ radicals will most likely be 
driven by mixed SA/MSA clusters clustering with both amines and ammonia.

\section{CONCLUSIONS}

New particle formation and growth from gaseous dimethyl sulfide (DMS) oxidized by hydroxyl radicals were studied experimentally in the AURA chamber and complemented by simulations with the ADCHAM model and quantum chemical calculations. Experimental observations show that aerosol mass yields are generally low, that particle formation and growth rates are slow, and that the formed aerosols consist predominately of methanesulfonic acid, rather than sulfate. ADCHAM and experimental data could be reconciled by implementing new oxidation mechanisms to reactions described in the Master Chemical Mechanism version 3.3.1 used in the model as well as hydroperoxymethyl thioformate (HPMTF), recently found to be formed via an autoxidation pathway of DMS. ADCHAM suggests that HPMTF serves as a gaseous sulfur reservoir, leading to a large portion of DMS not forming MSA and SA (see also the companion paper by Wollesen de Jonge et al. ${ }^{50}$ ). Both the ADCHAM model and quantum chemical calculations reveal that new particle formation rates are strongly dependent on the mixing ratio of ammonia. Quantum chemical calculations also demonstrate that the formed particles can have different mixtures of MSA and SA, which is decisive for the particles' properties such as their growth or water uptake potential.

In the marine atmosphere, there will always be some existing particles or cloud droplets resulting from long-range transport, sea spray emissions, local anthropogenic primary particle sources (e.g., shipping), or nucleation. These particles will be an adequate condensation sink for MSA and SA also without ammonia-mediated nucleation, and we expect that the secondary aerosol mass yields from DMS will not be limited by the presence of ammonia. In the chamber experiments discussed herein, ammonia becomes important for the secondary aerosol mass yields since we do not have initial seed particles and the chamber walls do contribute a substantial sink for both MSA and SA. However, such a major vapor deposition sink is not present in the atmosphere. In addition, recent observations at the coast of Antarctica and in the Arctic indicate that the observed new particle formation over the open ocean is driven by ammonia-SA clustering. ${ }^{99,100}$ Thus, although the ammonia concentrations in our chamber experiments are orders of magnitude higher than in polar marine environments, we expect that it is the same type of nucleation mechanism that dominates new particle formation.

\section{ASSOCIATED CONTENT}

\section{SI Supporting Information}

The Supporting Information is available free of charge at https://pubs.acs.org/doi/10.1021/acsearthspacechem.0c00333.

Experimental estimations of $\mathrm{OH}$ radicals in the chamber, details on the MSA calibration of the HR-ToF-AMS, general information on each experiment together with more details on the chemical composition and model parameters, and comparison between experimental and modeled data and modeled aerosol mass yield data and ACDC simulations (PDF)

\section{AUTHOR INFORMATION}

\section{Corresponding Authors}

Bernadette Rosati - Department of Chemistry, Aarhus University, Aarhus C DK-8000, Denmark; Faculty of Physics, University of Vienna, Vienna AT-1090, Austria;

(1) orcid.org/0000-0003-4930-3638;

Email: bernadette.rosati@chem.au.dk

Merete Bilde - Department of Chemistry, Aarhus University, Aarhus C DK-8000, Denmark; ㅇo이.org/0000-0002-

2112-514X; Email: bilde@chem.au.dk

\section{Authors}

Sigurd Christiansen - Department of Chemistry, Aarhus University, Aarhus C DK-8000, Denmark; 이이.org/ 0000-0002-6416-2522

Robin Wollesen de Jonge - Department of Chemistry, Aarhus University, Aarhus C DK-8000, Denmark

Pontus Roldin - Division of Nuclear Physics, Lund University, Lund SE-221 00, Sweden

Mads Mørk Jensen - Department of Chemistry, Aarhus University, Aarhus C DK-8000, Denmark

Kai Wang - Department of Chemistry, Aarhus University, Aarhus C DK-8000, Denmark

Shamjad P. Moosakutty - Department of Chemistry, Aarhus University, Aarhus C DK-8000, Denmark; Clean Combustion Research Center, King Abdullah University of Science and Technology, Thuwal KSA-23955, Saudi Arabia

Ditte Thomsen - Department of Chemistry, Aarhus University, Aarhus C DK-8000, Denmark; 이이.org/ 0000-0002-3110-8503

Camilla Salomonsen - Department of Chemistry, Aarhus University, Aarhus C DK-8000, Denmark

Noora Hyttinen - Nano and Molecular Systems Research Unit, University of Oulu, Oulu FI-90014, Finland; Department of Applied Physics, University of Eastern Finland, Kuopio FI-70211, Finland; (1) orcid.org/00000002-6025-5959

Jonas Elm - Department of Chemistry, Aarhus University, Aarhus C DK-8000, Denmark; ㅇo이.org/0000-00033736-4329

Anders Feilberg - Department of Biological and Chemical Engineering, Aarhus University, Aarhus N DK-8200, Denmark

Marianne Glasius - Department of Chemistry, Aarhus University, Aarhus C DK-8000, Denmark; (1) orcid.org/ 0000-0002-4404-6989

Complete contact information is available at:

https://pubs.acs.org/10.1021/acsearthspacechem.0c00333

\section{Notes}

The authors declare no competing financial interest.

\section{ACKNOWLEDGMENTS}

This research was supported by the Austrian Science Fund (FWF: J 3970-N36), Aarhus University, the European Research Council (ERC) under the European Union's Horizon 2020 Research and Innovation Program, Project SURFACE (Grant Agreement No. 717022), the Swedish Research Council Formas (Project no. 2018-01745-COBACCA), Swedish Research Council VR (project no. 2019-05006), the Faroese Research Foundation (Grant 0454), and the 
Independent Research Fund Denmark (Grant number 906400001B).

\section{REFERENCES}

(1) Lovelock, J. E.; Maggs, R. J.; Rasmussen, R. A. Atmospheric Dimethyl Sulfide and the Natural Sulfur Cycle. Nature 1972, 237, $452-453$.

(2) Andreae, M. O.; Raemdonck, H. Dimethyl Sulfide in the Surface Ocean and the Marine Atmosphere: A Global View. Science 1983, 221, 744-747.

(3) Kettle, A. J.; Andreae, M. O.; Amouroux, D.; Andreae, T. W.; Bates, T. S.; Berresheim, H.; Bingemer, H.; Boniforti, R.; Curran, M. A. J.; DiTullio, G. R; et al. A Global Database of Sea Surface Dimethylsulfide (DMS) Measurements and A Procedure To Predict Sea Surface DMS as a Function of Latitude, Longitude, and Month. Global Biogeochem. Cycles 1999, 13, 399-444.

(4) Andreae, M. O. Ocean-atmosphere Interactions in the Global Biogeochemical Sulfur Cycle. Marine Chem. 1990, 30, 1-29.

(5) Seinfeld, J. H.; Pandis, S. N. Atmospheric Chemistry and Physics: From Air Pollution to Climate Change, 3rd ed.; John Wiley \& Sons: Hoboken, NJ, 2016.

(6) Barnes, I.; Hjorth, J.; Mihalopoulos, N. Dimethyl Sulfide and Dimethyl Sulfoxide and Their Oxidation in the Atmosphere. Chem. Rev. 2006, 106, 940-975.

(7) Mardyukov, A.; Schreiner, P. R. Atmospherically Relevant Radicals Derived from the Oxidation of Dimethyl Sulfide. Acc. Chem. Res. 2018, 51, 475-483.

(8) Veres, P. R.; et al. Global airborne sampling reveals a previously unobserved dimethyl sulfide oxidation mechanism in the marine atmosphere. Proc. Natl. Acad. Sci. U.S.A. 2020, 117, 4505-4510.

(9) Charlson, R. J.; Lovelock, J. E.; Andreae, M. O.; Warren, S. G. Oceanic phytoplankton, atmospheric sulphur, cloud albedo and climate. Nature 1987, 326, 655-661.

(10) Ayers, G. P.; Cainey, J. M. The CLAW hypothesis: a review of the major developments. Environ. Chem. 2007, 4, 366-374.

(11) Vallina, S. M.; Simó, R. Re-visiting the CLAW hypothesis. Environ. Chem. 2007, 4, 384-387.

(12) Quinn, P.; Bates, T. The case against climate regulation via oceanic phytoplankton sulphur emissions. Nature 2011, 480, 51-6.

(13) Sipilä, M.; Berndt, T.; Petäjä, T.; Brus, D.; Vanhanen, J.; Stratmann, F.; Patokoski, J.; Mauldin, R. L.; Hyvärinen, A.-P.; Lihavainen, H.; Kulmala, M. The Role of Sulfuric Acid in Atmospheric Nucleation. Science 2010, 327, 1243-1246.

(14) Berresheim, H.; Eisele, F. L.; Tanner, D. J.; Mcinnes, L. M.; Ramseybell, D. C.; Covert, D. S. Atmospheric Sulfur Chemistry and Cloud Condensation Nuclei (CCN) Concentrations Over the Northeastern Pacific Coast. J. Geophys. Res. 1993, 98, 12701-12711.

(15) Eisele, F. L.; Tanner, D. J. Measurement of the Gas-phase Concentration of $\mathrm{H}_{2} \mathrm{SO}_{4}$ and Methane Sulfonic-acid and Estimates of $\mathrm{H}_{2} \mathrm{SO}_{4}$ Production and Loss in the Atmosphere. J. Geophys. Res. 1993, 98, 9001-9010.

(16) Mauldin, R. L.; Tanner, D. J.; Heath, J. A.; Huebert, B. J.; Eisele, F. L. Observations of $\mathrm{H}_{2} \mathrm{SO}_{4}$ and MSA During PEM-TropicsA. J. Geophys. Res. 1999, 104, 5801-5816.

(17) Berresheim, H.; Elste, T.; Tremmel, H. G.; Allen, A. G.; Hansson, H. C.; Rosman, K.; Maso, M. D.; Mäkelä, J. M.; Kulmala, M.; O'Dowd, C. D. Gas-aerosol Relationships of $\mathrm{H}_{2} \mathrm{SO}_{4}$, MSA, and $\mathrm{OH}$ : Observations in the Coastal Marine Boundary Layer at Mace Head, Ireland. J. Geophys. Res. 2002, 107, No. PAR5-1-PAR 5-12.

(18) Mauldin, R. L.; Cantrell, C. A.; Zondlo, M. A.; Kosciuch, E.; Ridley, B. A.; Weber, R.; Eisele, F. E. Measurements of $\mathrm{OH}, \mathrm{H}_{2} \mathrm{SO}_{4}$, and MSA During Tropospheric Ozone Production about the Spring Equinox (TOPSE). J. Geophys. Res. 2003, 108, 1-18.

(19) Bardouki, H.; Berresheim, H.; Vrekoussis, M.; Sciare, J.; Kouvarakis, G.; Oikonomou, K.; Schneider, J.; Mihalopoulos, N. Gaseous (DMS, MSA, $\mathrm{SO}_{2}, \mathrm{H}_{2} \mathrm{SO}_{4}$ and DMSO) and Particulate (Sulfate and Methanesulfonate) Sulfur Species over the Northeastern Coast of Crete. Atmos. Chem. Phys. 2003, 3, 1871-1886.
(20) Yokelson, R. J.; et al. Emissions from Biomass Burning in the Yucatan. Atmos. Chem. Phys. 2009, 9, 5785-5812.

(21) Klimont, Z.; Smith, S. J.; Cofala, J. The Last Decade of Global Anthropogenic Sulfur Dioxide: 2000-2011 Emissions. Environ. Res. Lett. 2013, 8, No. 014003.

(22) Amann, M.; Klimont, Z.; Wagner, F. Regional and Global Emissions of Air Pollutants: Recent Trends and Future Scenarios. Annu. Rev. Environ. Resour. 2013, 38, 31-55.

(23) Perraud, V.; Horne, J. R.; Martinez, A. S.; Kalinowski, J.; Meinardi, S.; Dawson, M. L.; Wingen, L. M.; Dabdub, D.; Blake, D. R.; Gerber, R. B.; Finlayson-Pitts, B. J. The Future of Airborne Sulfurcontaining Particles in the Absence of Fossil Fuel Sulfur Dioxide Emissions. Proc. Natl. Acad. Sci., U.S.A. 2015, 112, 13514-13519.

(24) Murphy, J. G.; Gregoire, P. K.; Tevlin, A. G.; Wentworth, G. R.; Ellis, R. A.; Markovic, M. Z.; VandenBoer, T. C. Observational Constraints on Particle Acidity using Measurements and Modelling of Particles and Gases. Faraday Discuss. 2017, 200, 379-395.

(25) U.S. EPA., https://www.epa.gov/air-trends/sulfur-dioxidetrends, (accessed Sept. 11, 2020).

(26) IPCC. Climate Change 2013: The Physical Science Basis, 2013.

(27) Merikanto, J.; Spracklen, D. V.; Mann, G. W.; Pickering, S. J.; Carslaw, K. S. Impact of nucleation on global CCN. Atmos. Chem. Phys. 2009, 9, 8601-8616.

(28) Tröstl, J.; et al. The role of low-volatility organic compounds in initial particle growth in the atmosphere. Nature 2016, 533, 527-531.

(29) Kulmala, M.; Kontkanen, J.; Junninen, H.; Lehtipalo, K.; Manninen, H. E.; Nieminen, T.; Petäjä, T.; Sipilä, M.; Schobesberger, S.; Rantala, P.; et al. Direct Observations of Atmospheric Aerosol Nucleation. Science 2013, 339, 943-946.

(30) Kirkby, J.; et al. Role of Sulphuric Acid, Ammonia and Galactic Cosmic Rays in Atmospheric Aerosol Nucleation. Nature 2011, 476, 429-433.

(31) Almeida, J.; Schobesberger, S.; Kürten, A.; et al. Molecular Understanding of Sulphuric Acid-Amine Particle Nucleation in the Atmosphere. Nature 2013, 502, 359-363.

(32) Jen, C. N.; McMurry, P. H.; Hanson, D. R. Stabilization of Sulfuric acid Dimers by Ammonia, Methylamine, Dimethylamine, and Trimethylamine. J. Geophys. Res. Atmos. 2014, 119, 7502-7514.

(33) Glasoe, W. A.; Volz, K.; Panta, B.; Freshour, N.; Bachman, R.; Hanson, D. R.; McMurry, P. H.; Jen, C. Sulfuric acid nucleation: an experimental study of the effect of seven bases. J. Geophys. Res.: Atmos. 2015, 120, 1933-1950.

(34) Olenius, T.; Kupiainen-Määttä, O.; Ortega, I. K.; Kurtén, T.; Vehkamäki, H. Free Energy Barrier in the Growth of Sulfuric AcidAmmonia and Sulfuric Acid-Dimethylamine Clusters. J. Chem. Phys. 2013, 139, No. 084312.

(35) Olenius, T.; Halonen, R.; Kurtén, T.; Henschel, H.; KupiainenMäättä, O.; Ortega, I. K.; Jen, C. N.; Vehkamäki, H.; Riipinen, I. New Particle Formation From Sulfuric Acid and Amines: Comparison of Mono-, Di-, and Trimethylamines. J. Geophys. Res. Atmos 2017, 122, $7103-7118$.

(36) Nadykto, A. B.; Yu, F.; Jakovleva, M. V.; Herb, J.; Xu, Y. Amines in the Earth's Atmosphere: A Density Functional Theory Study of the Thermochemistry of Pre-Nucleation Clusters. Entropy 2011, 13, 554-569.

(37) Nadykto, A. B.; Herb, J.; Yu, F.; Xu, Y. Enhancement in the Production of Nucleating Clusters due to Dimethylamine and Large Uncertainties in the Thermochemistry of Amine-Enhanced Nucleation. Chem. Phys. Lett. 2014, 609, 42-49.

(38) Nadykto, A. B.; Herb, J.; Yu, F.; Xu, Y.; Nazarenko, E. S. Estimating the Lower Limit of the Impact of Amines on Nucleation in the Earth's Atmosphere. Entropy 2015, 17, 2764-2780.

(39) Dawson, M. L.; Varner, M. E.; Perraud, V.; Ezell, M. J.; Gerber, R. B.; Finlayson-Pitts, B. J. Simplified Mechanism for New Particle Formation from Methanesulfonic Acid, Amines, and Water Via Experiments and $\mathrm{Ab}$ Initio Calculations. Proc. Natl. Acad. Sci. U.S.A. 2012, 109, 18719-18724.

(40) Chen, H.; Ezell, M. J.; Arquero, K. D.; Varner, M. E.; Dawson, M. L.; Gerber, R. B.; Finlayson-Pitts, B. J. New Particle Formation 
and Growth from Methanesulfonic Acid, Trimethylamine and Water. Phys. Chem. Chem. Phys. 2015, 17, 13699-13709.

(41) Chen, H.; Varner, M. E.; Gerber, R. B.; Finlayson-Pitts, B. J. Reactions of methanesulfonic acid with amines and ammonia as a source of new particles in air. J. Phys. Chem. B 2016, 120, 1526-1536.

(42) Chen, H.; Finlayson-Pitts, B. J. New Particle Formation from Methanesulfonic Acid and Amines/ammonia as a Function of Temperature. Environ. Sci. Technol. 2017, 51, 243-252.

(43) Arquero, K. D.; Gerber, R. B.; Finlayson-Pitts, B. J. The Role of Oxalic Acid in New Particle Formation from Methanesulfonic Acid, Methylamine, and Water. Environ. Sci. Technol. 2017, 51, 2124-2130.

(44) Arquero, K. D.; Xu, J.; Gerber, R. B.; Finlayson-Pitts, B. J. Particle Formation and Growth from Oxalic Acid, Methanesulfonic Acid, Trimethylamine and Water: A Combined Experimental and Theoretical Study. Phys. Chem. Chem. Phys. 2017, 19, 28286-28301.

(45) Perraud, V.; Xu, J.; Gerber, R. B.; Finlayson-Pitts, B. J. Integrated Experimental and Theoretical Approach to Probe the Synergistic Effect of Ammonia in Methanesulfonic Acid Reactions with Small Alkylamines. Environ. Sci.: Processes Impacts 2020, 22, 305-328.

(46) Bork, N.; Elm, J.; Olenius, T.; Vehkamäki, H. Methane Sulfonic Acid-enhanced Formation of Molecular Clusters of Sulfuric Acid and Dimethyl Amine. Atmos. Chem. Phys. 2014, 14, 12023-12030.

(47) Wen, H.; Wang, C.-Y.; Wang, Z.-Q.; Hou, X.-F.; Han, Y.-J.; Liu, Y.-R.; Jiang, S.; Huang, T.; Huang, W. Formation of Atmospheric Molecular Clusters Consisting of Methanesulfonic Acid and Sulfuric Acid: Insights from Flow Tube Experiments and Cluster Dynamics Simulations. Atmos. Environ. 2019, 199, 380-390.

(48) Roldin, P.; Eriksson, A. C.; Nordin, E. Z.; Hermansson, E.; Mogensen, D.; Rusanen, A.; Boy, M.; Swietlicki, E.; Svenningsson, B.; Zelenyuk, A.; Pagels, J. Modelling non-equilibrium secondary organic aerosol formation and evaporation with the aerosol dynamics, gasand particle-phase chemistry kinetic multilayer model ADCHAM. Atmos. Chem. Phys. 2014, 14, 7953-7993.

(49) Roldin, P.; et al. The role of highly oxygenated organic molecules in the Boreal aerosol-cloud-climate system. Nat. Commun. 2019, 10, No. 4370.

(50) Wollesen de Jonge, R.; Elm, J.; Rosati, B.; Christiansen, S.; Hyttinen, N.; Lüdemann, D.; Bilde, M.; Roldin, P. Secondary aerosol formation from dimethyl sulfide - improved mechanistic understanding based on smog chamber experiments and modelling. Atmos. Chem. Phys. Discuss. 2021, 2021, 1-33.

(51) Kristensen, K.; Jensen, L. N.; Glasius, M.; Bilde, M. The effect of sub-zero temperature on the formation and composition of secondary organic aerosol from ozonolysis of alpha-pinene. Environ. Sci.: Processes Impacts 2017, 19, 1220-1234.

(52) Seinfeld, J. H.; et al. Improving our fundamental understanding of the role of aerosol-cloud interactions in the climate system. Proc. Natl. Acad. Sci. U.S.A. 2016, 113, 5781-5790.

(53) Crump, J. G.; Flagan, R. C.; Seinfeld, J. H. Particle Wall Loss Rates in Vessels. Aerosol Sci. Technol. 1982, 2, 303-309.

(54) Leskinen, A.; Yli-Pirilä, P.; Kuuspalo, K.; Sippula, O.; Jalava, P.; Hirvonen, M.-R.; Jokiniemi, J.; Virtanen, A.; Komppula, M.; Lehtinen, K. E. J. Characterization and testing of a new environmental chamber. Atmos. Meas. Tech. 2015, 8, 2267-2278.

(55) de Gouw, J.; Warneke, C. Measurements of volatile organic compounds in the earth's atmosphere using proton-transfer-reaction mass spectrometry. Mass Spectrom. Rev. 2007, 26, 223-257.

(56) Cappellin, L.; Karl, T.; Probst, M.; Ismailova, O.; Winkler, P. M.; Soukoulis, C.; Aprea, E.; Märk, T. D.; Gasperi, F.; Biasioli, F. On Quantitative Determination of Volatile Organic Compound Concentrations Using Proton Transfer Reaction Time-of-Flight Mass Spectrometry. Environ. Sci. Technol. 2012, 46, 2283-2290.

(57) Sekimoto, K.; Li, S.-M.; Yuan, B.; Koss, A.; Coggon, M.; Warneke, C.; de Gouw, J. Calculation of the sensitivity of protontransfer-reaction mass spectrometry (PTR-MS) for organic trace gases using molecular properties. Int. J. Mass Spectrom. 2017, 421, 71-94.

(58) Taipale, R.; Ruuskanen, T. M.; Rinne, J.; Kajos, M. K.; Hakola, H.; Pohja, T.; Kulmala, M. Technical Note: Quantitative long-term measurements of VOC concentrations by PTR-MS; measurement, calibration, and volume mixing ratio calculation methods. Atmos. Chem. Phys. 2008, 8, 6681-6698.

(59) Liu, D.; Nyord, T.; Rong, L.; Feilberg, A. Real-time quantification of emissions of volatile organic compounds from land spreading of pig slurry measured by PTR-MS and wind tunnels. Sci. Total Environ. 2018, 639, 1079-1087.

(60) Decarlo, P. F.; Kimmel, J. R.; Trimborn, A.; Northway, M. J.; Jayne, J. T.; Aiken, A. C.; Gonin, M.; Fuhrer, K.; Horvath, T.; Docherty, K. S.; Worsnop, D. R.; Jimenez, J. L. Field-Deployable, High-Resolution, Time-of-Flight Aerosol Mass Spectrometer. Anal. Chem. 2006, 78, 8281-8289.

(61) Hodshire, A. L.; Campuzano-Jost, P.; Kodros, J. K.; Croft, B.; Nault, B. A.; Schroder, J. C.; Jimenez, J. L.; Pierce, J. R. The potential role of methanesulfonic acid (MSA) in aerosol formation and growth and the associated radiative forcings. Atmos. Chem. Phys. 2019, 19, 3137-3160.

(62) Phinney, L.; Leaitch, W. R.; Lohmann, U.; Boudries, H.; Worsnop, D. R.; Jayne, J. T.; Toom-Sauntry, D.; Wadleigh, M.; Sharma, S.; Shantz, N. Characterization of the aerosol over the subarctic north east Pacific Ocean. Deep Sea Res., Part II 2006, 53, 24102433. Canadian SOLAS: Subarctic Ecosystem Response to Iron Enrichment (SERIES).

(63) Zorn, S. R.; Drewnick, F.; Schott, M.; Hoffmann, T.; Borrmann, $S$. Characterization of the South Atlantic marine boundary layer aerosol using an aerodyne aerosol mass spectrometer. Atmos. Chem. Phys. 2008, 8, 4711-4728.

(64) McGrath, M. J.; Olenius, T.; Ortega, I. K.; Loukonen, V.; Paasonen, P.; Kurtén, T.; Kulmala, M.; Vehkamäki, H. Atmospheric Cluster Dynamics Code: A flexible method for solution of the birthdeath equations. Atmos. Chem. Phys. 2012, 12, 2345-2355.

(65) Jenkin, M. E.; Saunders, S. M.; Pilling, M. J. The tropospheric degradation of volatile organic compounds: a protocol for mechanism development. Atmos. Environ. 1997, 31, 81-104.

(66) Saunders, S. M.; Jenkin, M. E.; Derwent, R. G.; Pilling, M. J. Protocol for the development of the Master Chemical Mechanism, MCM v3 (Part A): tropospheric degradation of non-aromatic volatile organic compounds. Atmos. Chem. Phys. 2003, 3, 161-180.

(67) Jenkin, M. E.; Young, J. C.; Rickard, A. R. The MCM v3.3.1 degradation scheme for isoprene. Atmos. Chem. Phys. 2015, 15, 11433-11459.

(68) Frisch, M. J.; Trucks, G. W.; Schlegel, H. B.; Scuseria, G. E.; Robb, M. A.; Cheeseman, J. R.; Scalmani, G.; Barone, V.; Petersson, G. A.; Nakatsuji, H. et al.. Gaussian 16. Revision A.03; Gaussian, Inc.: Wallingford CT, 2016.

(69) Chai, J.; Head-Gordon, M. Long-range Corrected Hybrid Density Functionals with Damped Atom-atom Dispersion Corrections. Phys. Chem. Chem. Phys. 2008, 10, 6615-6620.

(70) Leverentz, H. R.; Siepmann, J. I.; Truhlar, D. G.; Loukonen, V.; Vehkamäki, H. Energetics of Atmospherically Implicated Clusters Made of Sulfuric Acid, Ammonia, and Dimethyl Amine. J. Phys. Chem. A 2013, 117, 3819-3825.

(71) Elm, J.; Bilde, M.; Mikkelsen, K. V. Assessment of Binding Energies of Atmopsheric Clusters. Phys. Chem. Chem. Phys. 2013, 15, $16442-16445$.

(72) Elm, J.; Kristensen, K. Basis Set Convergence of the Binding Energies of Strongly Hydrogen-Bonded Atmospheric Clusters. Phys. Chem. Chem. Phys. 2017, 19, 1122-1133.

(73) Schmitz, G.; Elm, J. Assessment of the DLPNO binding energies of strongly non-covalent bonded atmospheric molecular clusters. ACS Omega 2020, 5, 7601-7612.

(74) Elm, J.; Mikkelsen, K. V. Computational Approaches for Efficiently Modelling of Small Atmospheric Clusters. Chem. Phys. Lett. 2014, 615, 26-29.

(75) Myllys, N.; Elm, J.; Kurtén, T. Density Functional Theory Basis Set Convergence of Sulfuric Acid-Containing Molecular Clusters. Comp. Theor. Chem. 2016, 1098, 1-12. 
(76) Elm, J. An Atmospheric Cluster Database Consisting of Sulfuric Acid, Bases, Organics, and Water. ACS Omega 2019, 4, 1096510974.

(77) Chen, D.; Li, D.; Wang, C.; Liu, F.; Wang, W. Formation Mechanism of Methanesulfonic Acid and Ammonia Clusters: A Kinetics Simulation Study. Atmos. Environ. 2020, 222, No. 117161.

(78) Zhang, J.; Dolg, M. ABCluster: the artificial bee colony algorithm for cluster global optimization. Phys. Chem. Chem. Phys. 2015, 17, 24173-24181.

(79) Zhang, J.; Dolg, M. Global optimization of clusters of rigid molecules using the artificial bee colony algorithm. Phys. Chem. Chem. Phys. 2016, 18, 3003-3010.

(80) Kubečka, J.; Besel, V.; Kurtén, T.; Myllys, N.; Vehkamäki, H. Configurational sampling of noncovalent (atmospheric) molecular clusters: Sulfuric acid and guanidine. J. Phys. Chem. A 2019, 123, 6022-6033.

(81) Kildgaard, J. V.; Mikkelsen, K. V.; Bilde, M.; Elm, J. Hydration of Atmospheric Molecular Clusters: A New Method for Systematic Configurational Sampling. J. Phys. Chem. A 2018, 122, 5026-5036.

(82) Kildgaard, J. V.; Mikkelsen, K. V.; Bilde, M.; Elm, J. Hydration of Atmospheric Molecular Clusters II: Organic Acid-Water Clusters. J. Phys. Chem. A 2018, 122, 8549-8556.

(83) Temelso, B.; Mabey, J. M.; Kubota, T.; Appiah-Padi, N.; Shields, G. C. ArbAlign: A tool for optimal alignment of arbitrarily ordered isomers using the Kuhn-Munkres algorithm. J. Chem. Inf. Model. 2017, 57, 1045-1054.

(84) Riplinger, C.; Neese, F. An Efficient and Near Linear Scaling Pair Natural Orbital Based Local Coupled Cluster Method. J. Chem. Phys. 2013, 138, No. 034106.

(85) Riplinger, C.; Sandhoefer, B.; Hansen, A.; Neese, F. Natural Triple Excitations in Local Coupled Cluster Calculations with Pair Natural Orbitals. J. Chem. Phys. 2013, 139, No. 134101.

(86) Neese, F.. Software Update: The ORCA Program System, Version 4.0; Wiley Interdisciplinary Reviews: Computational Molecular Science, 2017, Vol. 8(1), p. e1327.

(87) Odum, J. R.; Hoffmann, T.; Bowman, F.; Collins, D.; Flagan, R. C.; Seinfeld, J. H. Gas/Particle Partitioning and Secondary Organic Aerosol Yields. Environ. Sci. Technol. 1996, 30, 2580-2585.

(88) Lide, D. CRC Handbook of Chemistry and Physics, 85th ed.; CRC Press: Boca Raton, FL, 2005; p 2661.

(89) Chen, T.; Jang, M. Secondary organic aerosol formation from photooxidation of a mixture of dimethyl sulfide and isoprene. Atmos. Environ. 2012, 46, 271-278.

(90) Lehtinen, K. E. J.; Kulmala, M. A model for particle formation and growth in the atmosphere with molecular resolution in size. Atmos. Chem. Phys. 2003, 3, 251-257.

(91) Kulmala, M.; Petäjä, T.; Nieminen, T.; Sipilä, M.; Manninen, H.; Lehtipalo, K.; Dal Maso, M.; Aalto, P.; Junninen, H.; Paasonen, P.; Riipinen, I.; Lehtinen, K.; Laaksonen, A.; Kerminen, V.-M. Measurement of the nucleation of atmospheric aerosol particles. Nat. Protoc. 2012, 7, 1651-1667.

(92) Manninen, H. E.; et al. EUCAARI ion spectrometer measurements at 12 European sites - analysis of new particle formation events. Atmos. Chem. Phys. 2010, 10, 7907-7927.

(93) Yli-Juuti, T.; Nieminen, T.; Hirsikko, A.; Aalto, P. P.; Asmi, E.; Hõrrak, U.; Manninen, H. E.; Patokoski, J.; Dal Maso, M.; Petää, T.; Rinne, J.; Kulmala, M.; Riipinen, I. Growth rates of nucleation mode particles in Hyytiälä during 2003 - 2009: variation with particle size, season, data analysis method and ambient conditions. Atmos. Chem. Phys. 2011, 11, 12865-12886.

(94) Pieber, S. M.; et al. Inorganic Salt Interference on $\mathrm{CO} 2+$ in Aerodyne AMS and ACSM Organic Aerosol Composition Studies. Environ. Sci. Technol. 2016, 50, 10494.

(95) Drewnick, F.; Hings, S. S.; Alfarra, M. R.; Prevot, A. S. H.; Borrmann, S. Aerosol quantification with the Aerodyne Aerosol Mass Spectrometer: detection limits and ionizer background effects. Atmos. Meas. Tech. 2009, 2, 33-46.

(96) Drewnick, F.; Diesch, J. M.; Faber, P.; Borrmann, S. Aerosol mass spectrometry: Particle-vaporizer interactions and their con- sequences for the measurements. Atmos. Meas. Tech. 2015, 8, 38113830.

(97) Kukui, A.; Borissenko, D.; Laverdet, G.; Bras, G. Gas-Phase Reactions of $\mathrm{OH}$ Radicals with Dimethyl Sulfoxide and Methane Sulfinic Acid Using Turbulent Flow Reactor and Chemical Ionization Mass Spectrometry. J. Phys. Chem. A 2003, 107, 5732.

(98) Hoffmann, E. H.; Tilgner, A.; Schrödner, R.; Bräuer, P.; Wolke, R.; Herrmann, H. An advanced modeling study on the impacts and atmospheric implications of multiphase dimethyl sulfide chemistry. Proc. Natl. Acad. Sci. U.S.A. 2016, 113, 11776-11781.

(99) Jokinen, T.; Sipilä, M.; Kontkanen, J.; Vakkari, V.; Tisler, P.; Duplissy, E.-M.; Junninen, H.; Kangasluoma, J.; Manninen, H. E.; Petäjä, T.; Kulmala, M.; Worsnop, D. R.; Kirkby, J.; Virkkula, A.; Kerminen, V.-M. Ion-induced sulfuric acid-ammonia nucleation drives particle formation in coastal Antarctica. Sci. Adv. 2018, 4, No. eaat9744.

(100) Beck, L. J.; et al. Differing Mechanisms of New Particle Formation at Two Arctic Sites. Geophys. Res. Lett. 2021, 48, No. e2020GL091334. 